\title{
Water sensitive papers simulation to assess deposits on targets
}

\author{
Emanuele Cerruto, Claudia Aglieco \\ Department DiGeSA, Section of Mechanics and Mechanisation, University of Catania, Catania, Italy
}

\begin{abstract}
Aim of the study is to assess the possibility to use water sensitive papers to estimate, beside the superficial coverage, also the amount of deposit on the target at varying the spray features. To point out the main quantities influencing the deposit, the behaviour of the water sensitive papers was simulated by assuming some simplifying hypotheses: log-normal distribution of the diameter population of the drops and circular spots. Several images (630) of water sensitive papers, sprayed with drops of different mean diameter (from 100 up to $500 \mu \mathrm{m})$, constant coefficient of variation $(0.50)$, and theoretical percentage of covered surface ranging from 10 up to $100 \%$, were produced by means of simulation. These images were considered as effective water sensitive paper images and then analysed by means of an image processing software. The correlations between measured and effective values were studied and they allowed for an estimate of deposit and spray features from the image data. This implies that the analysis of the water sensitive paper images allows the determination of more complex parameters such as the unitary deposit and the impact density, all data strictly related to the efficacy of a phytosanitary treatment.
\end{abstract}

\section{Introduction}

Several studies have pointed out that, even if the evaluation of a phytosanitary treatment should be related to the biological results, a proper calibration of the sprayer is necessary in order to avoid off-target losses, to apply the pesticide uniformly on the canopy or where it

Correspondence: Cerruto Emanuele, Dipartimento DiGeSA, Via S. Sofia 100, 95123 Catania, Italy.

Tel. +39.095.7147514 - Fax: +39.095 .7147600 .

E-mail: ecerruto@unict.it

Key words: pesticides, image analysis, drop pulverisation.

Contributions: the authors contributed equally.

Conflict of interests: the authors declare no potential conflict of interests.

(C) Copyright E. Cerruto and C. Aglieco, 2013

Licensee PAGEPress, Italy

Journal of Agricultural Engineering 2013; XLIV(s2):e80

doi:10.4081/jae.2013.s2.e80

This article is distributed under the terms of the Creative Commons Attribution Noncommercial License (by-nc 3.0) which permits any noncommercial use, distribution, and reproduction in any medium, provided the original author(s) and source are credited. is required, and to minimise the impact on the environment (Vanella et al., 2010). The European Directive 2009/127/CE recognises the use of pesticides "as posing threats both to human health and the environment" and that "the design, construction and maintenance of machinery for pesticide application play a significant role in reducing the adverse effects of pesticides on human health and the environment". The European Directive 2009/128/CE enforces these aspects and states that a "common legal framework for achieving a sustainable use of pesticides should be established, taking account of precautionary and preventive approaches".

The assessment of the distribution of the active substance on the canopy (leaves, fruits) is currently performed by measuring via proper techniques (Cerruto, 2007) the amount of mixture or microelements, sprayed together with the mixture, that reach the target, or by analysing the impacts of the drops on suitable artificial targets (Salyani and Fox, 1999; Cerruto and Failla, 2003; Pergher et al., 2008).

The most common artificial targets are water sensitive papers and PVC targets covered with silicon oil. Water sensitive papers allow for a quick assessing of the superficial coverage, while PVC targets allow for a better study of the spots, as they also can be used with high volume rates. The spot size distributions in the two targets are strictly correlated (Cerruto et al., 2009).

In the present study the behaviour of water sensitive papers was simulated, so to estimate, in addition to the superficial coverage, the spray features and the amount of deposit on the target. In a previous study (Aglieco and Cerruto, 2012), producing by means of simulation some images of water sensitive papers sprayed with droplets of different pulverisation degree and different coefficients of variation of the droplet diameter, it was found a significant correlation between spray volume collected by the water sensitive papers and data achieved from the images. In this paper the Authors intend to investigate this aspect thoroughly, by extending the study to sprays characterised by wider ranges of mean diameters and to water sensitive papers with greater superficial coverage.

\section{Materials and methods}

\section{The experimental activity}

Sprays with different mean drop diameter were simulated, ranging from 100 up to $500 \mu \mathrm{m}$ with step of $20 \mu \mathrm{m}$. Drop diameters were lognormal distributed, with constant (50\%) coefficient of variation (CV). Images of water sensitive papers $2 \mathrm{~cm} \times 7 \mathrm{~cm}$ in size were produced, with theoretical values of superficial coverage (not considering overlapping), ranging from 10 up to $100 \%$ with step of $10 \%$. For each value of mean diameter and theoretical superficial coverage, three replicates were carried out, so producing a total of 630 images.

Simulation was developed according to the following procedure:

1. Given mean diameter $\left(D_{m}\right)$ and $C V$, produce the drop diameter population $\left(D_{d}\right)$. The number of drops was preliminarily computed on the basis of the desired theoretical value of superficial coverage. 
2. Given the drop diameters $D_{d}(\mu \mathrm{m})$, produce the corresponding spot diameters $D_{s}(\mu \mathrm{m})$. Spot diameters were estimated by analysing the spread factor (ratio between spot diameter and drop diameter, Figure 1, Novartis) and using the equation:

$$
D_{s}=0.938 \cdot D_{d}^{1.143}
$$

3. Produce the water sensitive paper images by randomly allocating the spots, circular shaped, up to the desired theoretical superficial coverage. Images were produced with a resolution of $1200 \mathrm{dpi}$, enough to detect spots of $24 \mu \mathrm{m}$ in diameter.

4. Store all the main data used to produce each image (drop diameter population, number, total volume $(\mu \mathrm{L})$, and volume mean diameter (VMD) of the drops).

All the procedures were implemented by using the open source software $R$ (R Development Core Team, 2012).

\section{Data analysis}

The images produced via simulation were analysed by means of the ImageJ (Abramoff et al., 2004) software as effective water sensitive paper images. The software detects the particles, without distinguishing among overlapped particles, and provides some data for each image, among which percentage of covered surface, number of spots and area of each spot were selected.

Subsequently, studying the area of each spot detected by ImageJ, other quantities were computed, among which:

the equivalent diameter $D_{s}^{\prime}$ of each spot (that of the circle with the same area);

the diameter of the drop $D_{d}^{\prime}$ capable of producing a spot with diam eter $D_{s}^{\prime}$ (the calculation was carried out by inverting Equation 1); the $\mathrm{CV}$ and the mean diameter $D_{m}^{\prime}$ of these drops; the volume transported by these drops.
All these data were correlated with the theoretical ones used to produce the images so to analyse their trend at varying spray and image features. All the statistical analyses and graphical representations were carried out by using the same software $R$.

\section{Results and discussion}

\section{Superficial coverage}

Figure 2 show two examples of the simulated water sensitive papers.

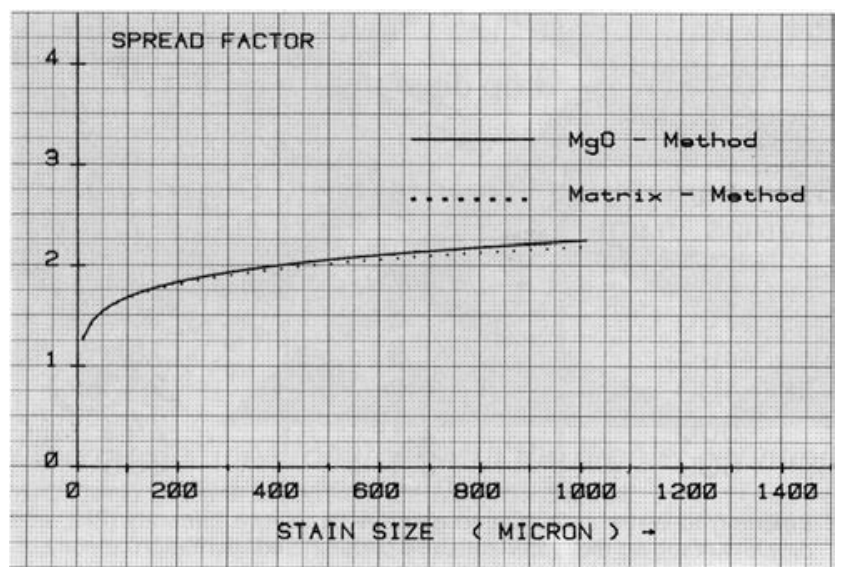

Figure 1. Spread factor $v s$ spot diameter (Novartis).

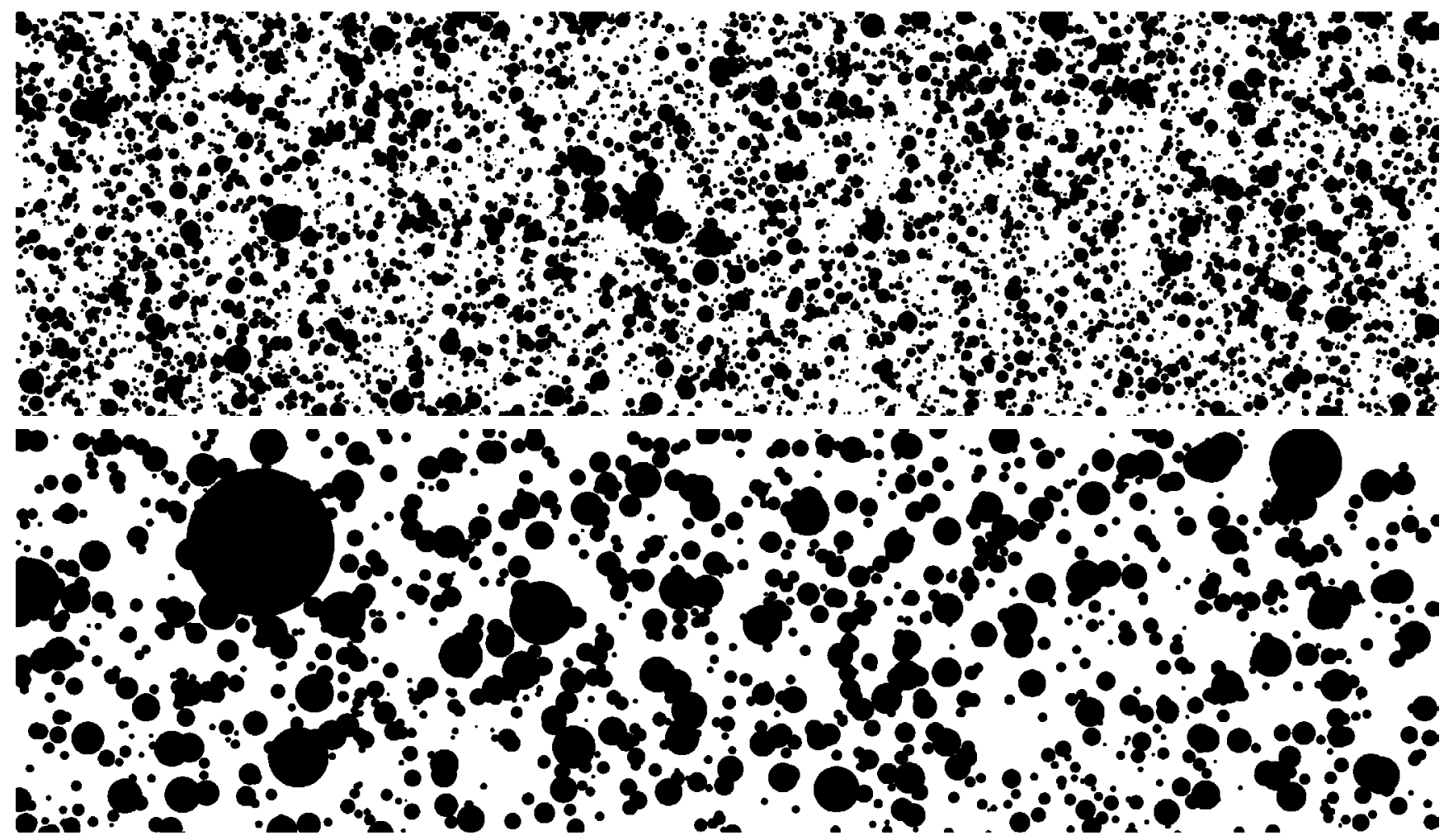

Figure 2. Examples of water sensitive papers produced by the simulations. 
The first refers to a spray with mean drop diameter equal to $160 \mu \mathrm{m}$, theoretical value of percentage of covered surface equal to $50 \%$, and theoretical deposit equal to $1.97 \mu \mathrm{L} / \mathrm{cm}^{2}$. The corresponding values for the second image are $320 \mu \mathrm{m}, 50 \%$ and $3.65 \mu \mathrm{L} / \mathrm{cm}^{2}$, respectively.

The theoretical $\left(S_{T}, \%\right)$ percentage of covered surface is related to the measured one $\left(S_{M}, \%\right)$ by the equation:

$$
S_{T}=101.7827 \cdot \ln \frac{100}{100-S_{M}}
$$

reported in Figure 3. The coefficient of determination $R^{2}$ is equal to 0.9988 , highly significant. When the measured value of percentage of covered surface increases towards $100 \%$, the theoretical one tends to infinity asymptotically. Moreover, the result is independent from the mean drop diameter. According to the equation (2), when the theoretical percentage of covered surface ranges from 10 up to $100 \%$, the measured one ranges from 9.4 up to $62.5 \%$ and then the overlap ranges from 0.6 up to $37.5 \%$.

\section{Unitary deposit}

Figure 4 reports the trends of the theoretical deposit $v s$. the measured percentage of covered surface, at varying the mean drop diameter. The trends are well explained by quadratic relations, whose coefficients are functions of the mean drop diameter. The coefficients of determination range from 0.9887 up to 0.9995 , highly significant. So, when the drop diameter $\mathrm{CV}$ is equal to 0.5 , the unitary deposit can be estimated by knowing mean drop diameter and percentage of covered surface only.

However, in the previous study (Aglieco and Cerruto, 2012), where CVs equal to $0.4,0.5$ and 0.6 were considered, it was found that the relations between unitary deposit and percentage of covered surface are affected by the CV values, and then an appropriate estimate of this parameter should be extracted from the images. This aspect will be investigated in further studies.

As an alternative way, the unitary deposit was computed by analysing

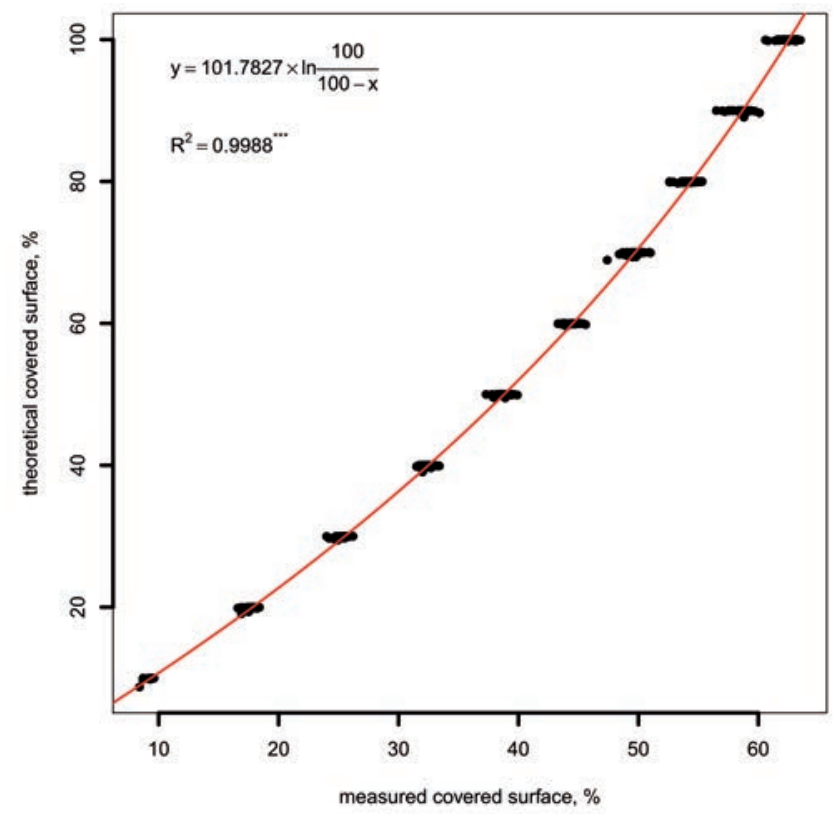

Figure 3. Correlation between theoretical and measured percentage of covered surface. the spots, namely by computing the equivalent diameters $D_{s}^{\prime}$ of the spots and then the corresponding drop diameters $D_{d}^{\prime}$. In the previous study (Aglieco and Cerruto, 2012), the relation between theoretical deposit and deposit computed by analysing the spots, was found to be independent from the drop diameter $\mathrm{CV}$, even if this aspect should be more investigated by considering wider ranges of $\mathrm{CV} s$.

According to this approach, the relation between deposit computed by analysing the spots $V_{C}\left(\mu \mathrm{L} / \mathrm{cm}^{2}\right)$ and theoretical deposit $V_{T}\left(\mu \mathrm{L} / \mathrm{cm}^{2}\right)$ was that showed in Figure 5. The interpolating functions are of the form:

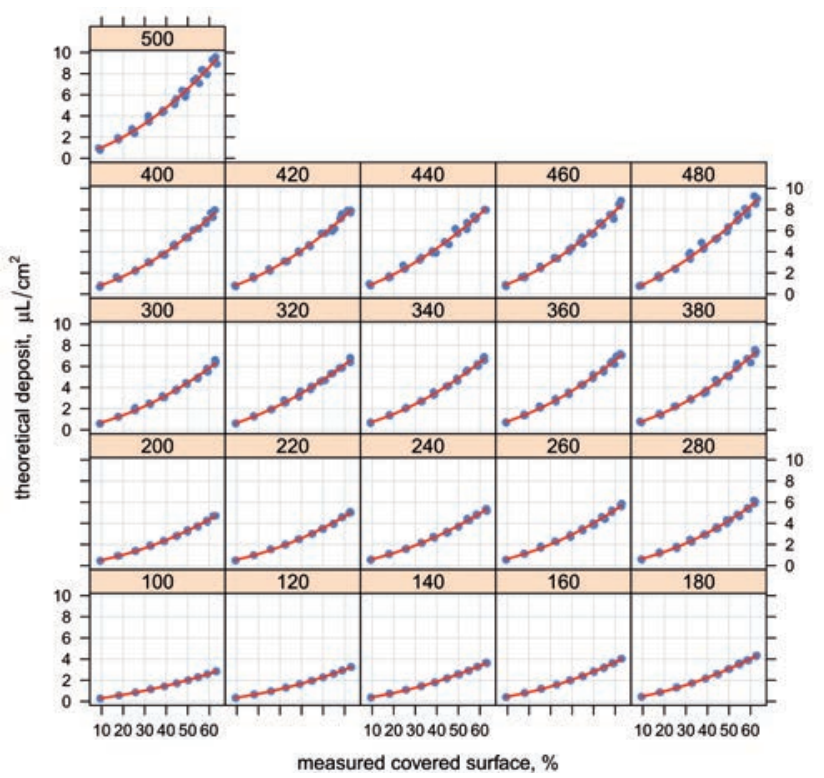

Figure 4. Correlation between measured percentage of covered surface and theoretical deposit at varying mean drop diameter $(\mu \mathrm{m})$.

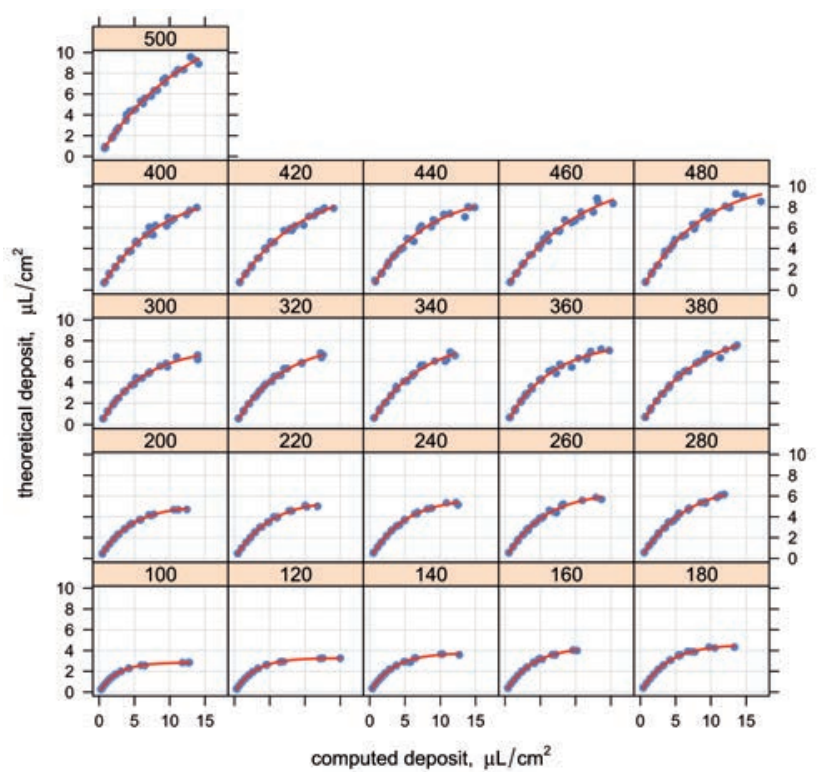

Figure 5. Correlation between computed and theoretical deposit at varying mean drop diameter $(\mu \mathrm{m})$. 
$V_{T}=a_{0}+a_{1} \cdot e^{-a_{2} \cdot V_{C}}$

being $a_{0}, a_{1}$ and $a_{2}$ coefficients depending on the mean drop diameter. If the independence from the drop diameter $\mathrm{CV}$ is confirmed, only an estimate of the mean drop diameter is necessary to compute the deposit starting from the spot analysis on water sensitive paper images.

This estimate can be achieved by computing the linear regression $D_{m}^{\text {, }}$ of on $S_{M}$ considering the images with $S_{M}<40 \%$ only, and predicting the response at $S_{M}=5 \%$. The error was always between $4.2 \%$ and $3.6 \%$.

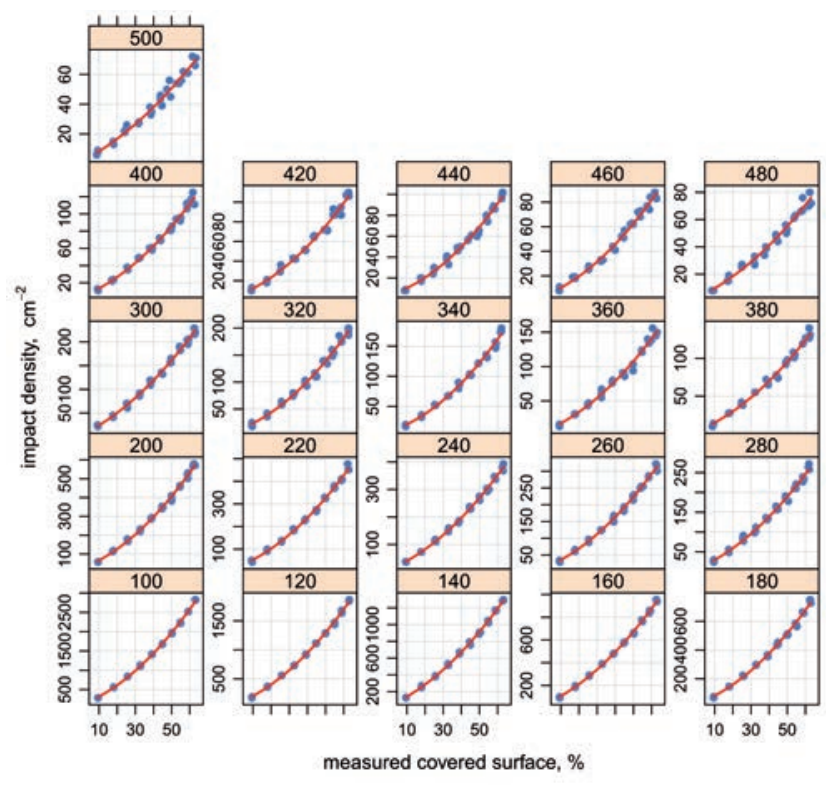

Figure 6. Correlation between impact density and measured percentage of covered surface at varying mean drop diameter $(\mu \mathrm{m})$.

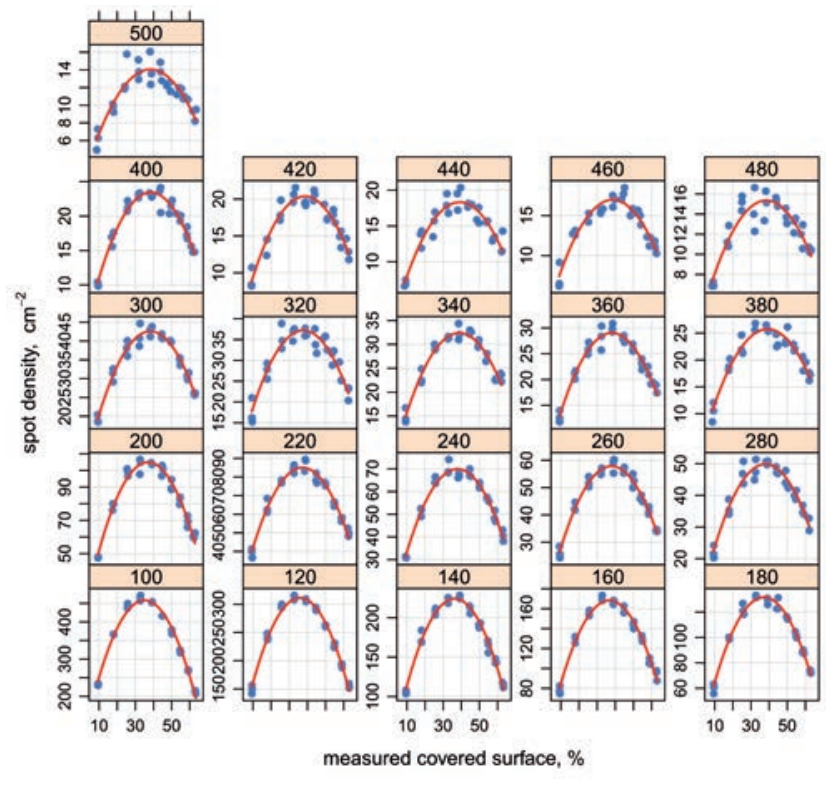

Figure 7. Correlation between spot density and measured percentage of covered surface at varying mean drop diameter $(\mu \mathrm{m})$.

\section{Impact and spot density}

The impact density (number of drops per square centimetre) increases when the percentage of covered surface increases (Figure 6). The regression equations, depending on the mean drop diameters, are of quadratic type, with coefficients of determination ranging from 0.9816 up to 0.9993 . As an influence of the drop diameter CV should be expected, even this aspect will be investigated thoroughly in the prosecution of the research.

The spot density (number of spots per square centimetre), at the contrary, due to the overlapping, increases up to a maximum, and then decreases (Figure 7). The maximum is reached when the percentage of covered surface is between 35 and $39 \%$, confirming the results of the previous study, and decreases when the mean drop diameter increases.

\section{Conclusions}

The results of this study confirm and enforce those obtained in the previous one (Aglieco and Cerruto, 2012). In particular:

Theoretical and measured percentage of covered surface are related by a simple relation (Equation 2), independently from the spray features. This allows for a quick estimate of the overlap, potentially cause of run-off.

The theoretical deposit is related to the measured percentage of covered surface by a quadratic relation, but influenced by the mean drop diameter. As the previous study revealed an influence of the drop diameter $\mathrm{CV}$, a more accurate estimate of the deposit requires an analysis of the spots.

The analysis of the spots allows for an estimate of the deposit higher than theoretical one, but computed and theoretical deposit are strictly correlated. In the previous study, the regression equations were independent from the drop diameter $\mathrm{CV}$, but dependent only from the mean drop diameter. A dedicated study on this aspect, by considering wider ranges of $\mathrm{CV}$, will be developed in the prosecution of the research.

The effective mean drop diameter can be achieved from the images by using the regression equation of the computed mean drop diameter on the measured percentage of covered surface.

All considered, the analysis of the water sensitive paper images allows for a complete description of the treatment in terms of unitary deposits, drop diameter, spot and impact density. Further studies are necessary to cover other situations (different $\mathrm{CV}$, different diameter distributions, lower mean diameters) and to experimentally verify the models.

\section{References}

Abramoff M.D., Magelhaes P.J., Ram S.J. Image Processing with ImageJ. Biophotonics International, 2004, vol. 11, issue 7, 36-42.

Aglieco C., Cerruto E. Theoretical analysis of sprays by simulation on water sensitive papers (Italian). Proceedings of Giornate Fitopatologiche 2012, Milano Marittima (RA), Italy, March 13-16, vol. 2, 79-88.

Cerruto E., Failla S. Spray trials in vineyard using air carrier sprayer. 2nd part: artificial targets analysis (Italian). Riv. di Ing. Agr., 2003, $3,13-22$.

Cerruto E. Influence of Airflow Rate and Forward Speed on the Spray Deposit in Vineyard, J. of Ag. Eng.-Riv. di Ing. Agr., 2007, 1, 7-14.

Cerruto E., Balloni S., Conti A., Caruso L. Caratteristiche di bersagli artificiali per lo studio delle gocce in prove di irrorazione. 
Proceedings on CD-ROM of the IX National Congress AIIA 2009 "Ricerca e innovazione nell'ingegneria dei biosistemi agro-territoriali”, Ischia (NA), September 12-16, 2009.

Directive 2009/127/EC of the European Parliament and of the Council of 21 October 2009 amending Directive 2006/42/EC with regard to machinery for pesticide application.

Directive 2009/128/EC of the European Parliament and of the Council of 21 October 2009 establishing a framework for Community action to achieve the sustainable use of pesticides.

Novartis. Water-sensitive paper for monitoring spray distribution. 5th edition.

Pergher G., Petris R., Biocca M., Menesatti P. Prime verifiche di campo di un'irroratrice schermata ad aeroconvezione di nuova concezione. Proceedings of Giornate Fitopatologiche 2008, Cervia (RA), March 12-14, vol. 2, 51-58.

R Development Core Team. 2012. R: A Language and Environment for Statistical Computing. R Foundation for Statistical Computing, Vienna, Austria. ISBN 3-900051-07-0, URL http://www.Rproject.org.

Salyani M., Fox R.D. Evaluation of spray quality by oil- and water sensitive papers. Transactions of the ASAE, 1999, vol. 42(1), 37-43.

Vanella G., Marucco P., Balsari P. È possibile ottenere il numero di impatti (gocce) per unità di superficie desiderato? Proceedings of Giornate Fitopatologiche 2010, Cervia (RA), March 9-12, vol. 2, 27-34. 